\title{
LINFOMI A CELLULE B E INFEZIONI DA Chlamydiae
}

\section{Ponzoni M.}

\section{U. O. di Anatomia Patologica; IRCCS \\ Ospedale San Raffaele; Milano}

I meccanismi alla base dello sviluppo dei linfomi nonHodgkin (NHL) sono in gran parte ancora sconosciuti. Una porzione consistente di taluni tipi di NHL sembra essere legata ad alcuni elementi non neoplastici, che rappresentano il microambiente in cui il linfoma si sviluppa.

Tra i fattori favorenti l'attivazione del microambiente sono stati chiamati in causa alcuni agenti infettivi, in virtù delle associazioni riportate fra Helicobacter pylori, Borrelia burgdorferi e Campylobacter jejuni e i lin-

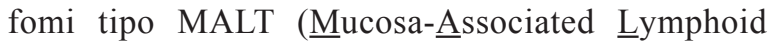
Tissue) insorti, rispettivamente, nello stomaco, cute e piccolo intestino. In questo contesto, è stata recentemente descritta dal nostro gruppo l'esistenza di un'associazione fra l'infezione da Chlamydia psittaci (Cps) e lo sviluppo dei linfomi tipo MALT degli annessi oculari (OAL). In particolare, in una consistente quota di pazienti con OAL è stata evidenziata tramite PCR la presenza di $C p s$ nei tessuti tumorali. Inoltre, in circa $2 / 3$ dei pazienti con OAL associati a Cps, è stata riscontrata la presenza del microrganismo nelle cellule mononucleate del sangue periferico (PBMC). La valutazione della possibile associazione con gli altri due tipi più frequenti di Chlamydia, vale a dire la C. trachomatis e la C. pneumoniae, non ha rilevato nessun dato in tal senso. Indagini immunoistochimiche hanno dimostrato la presenza della $C p s$ nei macrofagi presenti nel contesto del linfoma e non nelle cellule tumorali stesse, a ulteriore riprova dell'ipotesi di un attivo coinvolgimento microambientale. Conseguentemente, la persistenza di Cps potrebbe favorire lo sviluppo e il mantenimento degli OAL. I dati precedentemente descritti hanno portato a importanti implicazioni sul piano terapeutico.

Lo spettro delle indagini in corso presso il nostro gruppo è rivolto al chiarimento di plurimi argomenti attualmente irrisolti. Innanzitutto, le recenti modifiche non solo dal punto di vista delle nomenclature, nell'approccio classificativo della $C p s$ ha indotto a formulare l'ipotesi della presenza di altri microrganismi filogeneticamente correlati alla $C p s$ e potenzialmente coinvolti negli OAL. In secondo luogo, sono in corso indagini di screening molecolare per verificare la presenza della $C p s$ in NHL istologicamente differenti dai linfomi MALT e in sedi di insorgenza diverse dagli OAL.

In aggiunta a ciò, è necessario ampliare il concetto di "antigen-driven disorders" degli OAL alla possibile 
presenza di regioni immunoglobuliniche codificanti per regioni note della $C p s$, nel contesto delle cellule linfomatose, così come è necessario stratificare a fini prognostici i pazienti con OAL sulla base della presenza di eventuali alterazioni cromosomiche.

Infine, è necessario definire con maggior precisione le caratteristiche del microambiente che accompagna tali linfomi, soprattutto per quanto riguarda l'aspetto immunofenotipico/funzionale degli elementi immunitari non neoplastici d'accompagnamento nelle lesioni tumorali. 